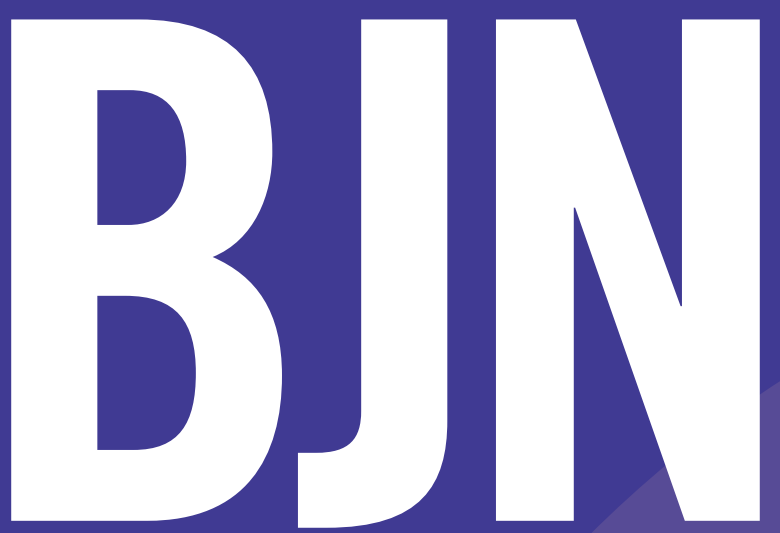

\title{
BRITISH JOURNAL OF NUTRITION
}

Volume: 120

Supplement 1

August 2018

An International Journal of Nutritional Science

Supplement

Growing science in pet nutrition

Proceedings of the WALTHAM International Nutritional Sciences Symposium 18-21 October, 2016

Chicago, Illinois, USA

Guest Editors: D'Ann Finley, Andrea Fascetti, Richard Butterwick, Geert Janssens,

Adronie Verbrugghe, Nick Cave, Alexander German, George Fahey Jr., Penelope Morris and Vincent Biourge

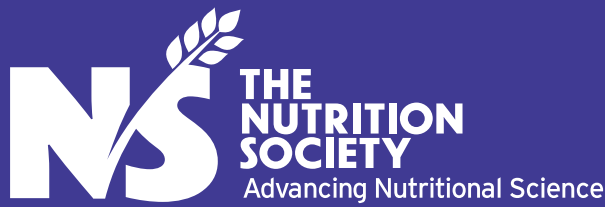


British Journal of Nutrition

120 Supplement 1 August 2018

Growing science in pet nutrition

Proceedings of the WALTHAM International Nutritional Sciences Symposium

October 18-21, 2016 Chicago, Illinois, USA

Guest editors:

D'Ann Finley

Andrea Fascetti

Richard Butterwick

Geert Janssens

Adronie Verbrugghe

Nick Cave

Alexander German

George Fahey Jr.

Penelope Morris

Vincent Biourge

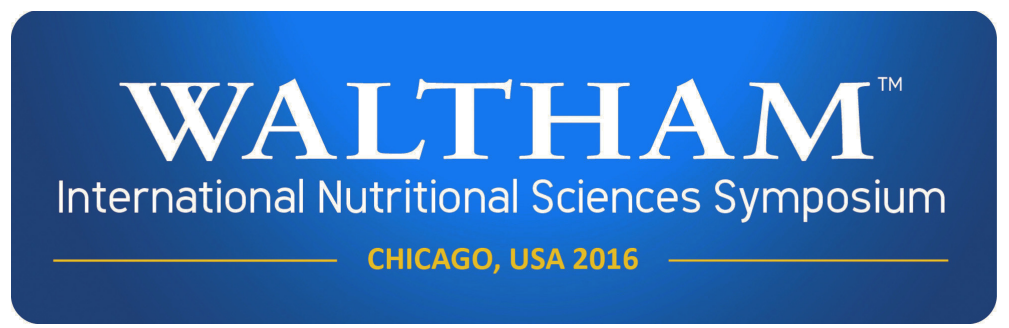

The papers included in this supplement were invited by the Guest Editors and have undergone the standard journal formal review process. They may be cited. The Guest Editors declare no conflict of interest. 